\title{
Mathematical Model and Experimental Results for Cryogenic Densification and Sub-cooling Using a Submerged Cooling Source
}

\author{
J.K. Partridge ${ }^{1}$, J.W. Tuttle ${ }^{2}$, W.U. Notardonato ${ }^{1}$, W.L. Johnson ${ }^{1}$ \\ ${ }^{1}$ Cryogenics Test Laboratory, Kennedy Space Center \\ ${ }^{2}$ ASRC Aerospace, Kennedy Space Center
}

\begin{abstract}
Among the many factors that determine overall rocket performance, propellant density is important because it affects the size of the rocket. Thus, in order to decrease the size of a rocket, it may be desirable to increase the density of propellants. This study analyzes the concept of increasing the propellant density by employing a cooling source submerged in the liquid propellant. A simple, mathematical model was developed to predict the rate of densification and the propellant temperature profile. The mathematical model is generic and applicable to multiple propellants. The densification rate was determined experimentally by submerging a cooling source in liquid oxygen at constant, positive pressure, and measuring the time rate of change in temperature with respect to vertical position. The results from the mathematical model provided a reasonable fit when compared to experimental results.
\end{abstract}

\section{Introduction}

In an attempt to lower the inert mass of a launch vehicle, propellant densification is viewed as a method to reduce the propellant tank volume and a means to reduce the mass of the propellant tank and, therefore, increase payload mass. Many have conducted studies for propellant densification [1] [2] [3]. Most of the studies suggest to place the densification operation between the ground storage tank and launch vehicle [4] [5] [6]. This paper investigates placement of the densification operation within the ground storage tank. Also, this paper predicts the rate of propellant densification using a cooling source within the liquid propellant and compares the prediction to experimental results. This work is similar to the Integrated Refrigeration and Storage method proposed by Notardonato [7] [8].

\section{Material and methods}

\subsection{Test Article}

The main test article is comprised of a 400L dewar with a $0.254 \mathrm{~m}$ neck opening that accepts a male bayonet. Eden Cryogenics constructed the dewar using 304 stainless steel with an inside diameter of $0.76 \mathrm{~m}$ and a maximum allowable working pressure of $515 \mathrm{kPa}$ absolute. The male bayonet, also constructed with 304 stainless steel, incorporated two fluid penetrations and two instrumentation cable penetration. A heat exchanger extended below the male bayonet and connected to the male bayonet by $0.013 \mathrm{~m}$ and $0.025 \mathrm{~m}$ stainless steel tubing, which insulated with a thickness of $0.076 \mathrm{~m}$ of polytetrafluoroethylene. The fluid penetrations allowed coolant to enter the heat exchanger through the $0.013 \mathrm{~m}$ diameter tubing and exit the heat exchanger through the $0.025 \mathrm{~m}$ tubing. The heat exchanger was $0.013 \mathrm{~m}$ diameter copper tubing with annular fins totaling $0.36 \mathrm{~m}$ in length.

Peripheral equipment included a liquid nitrogen source, liquid nitrogen subcooler, and gaseous oxygen source. Liquid nitrogen, in $110 \mathrm{~L}$ and $180 \mathrm{~L}$ dewars saturated at $0.21 \mathrm{kPag}$, provided the cooling fluid for the heat exchanger inside the main test article. The liquid nitrogen flowed through a simple liquid nitrogen subcooler to ensure the liquid nitrogen is subcooled before entering the main test article. The liquid nitrogen subcooler consisted of copper heat exchanger submerged in liquid nitrogen subjected to atmospheric pressure. The gaseous oxygen source, from a 43L k-bottle at ambient temperature and an initial pressure of $16.6 \mathrm{kPag}$, provided the means to control the pressure within the main test article.

\subsection{Instrumentation}

A micarta instrumentation rake was attached to the bottom of the neck flange. A total of 28 RTD measured the temperature inside the test dewar. Twenty RTD measured the temperature of position in vertical and the remaining eight RTD measured the horizontal temperature at two vertical positions. One pressure transducer measured the test dewar pressure, while a separate pressure transducer measured the pressure in the coolant system. Two thermocouples measured the temperatures of the coolant entering and exiting the male bayonet. Two mass flow controllers measured and controlled the quantity of coolant flowing through the heat exchanger and the quantity of gaseous oxygen flowing into the test dewar. The specifications for the nitrogen and oxygen were MILPRF-27401F Grade B and MIL-PRF-25508G Grade F, respectively. 


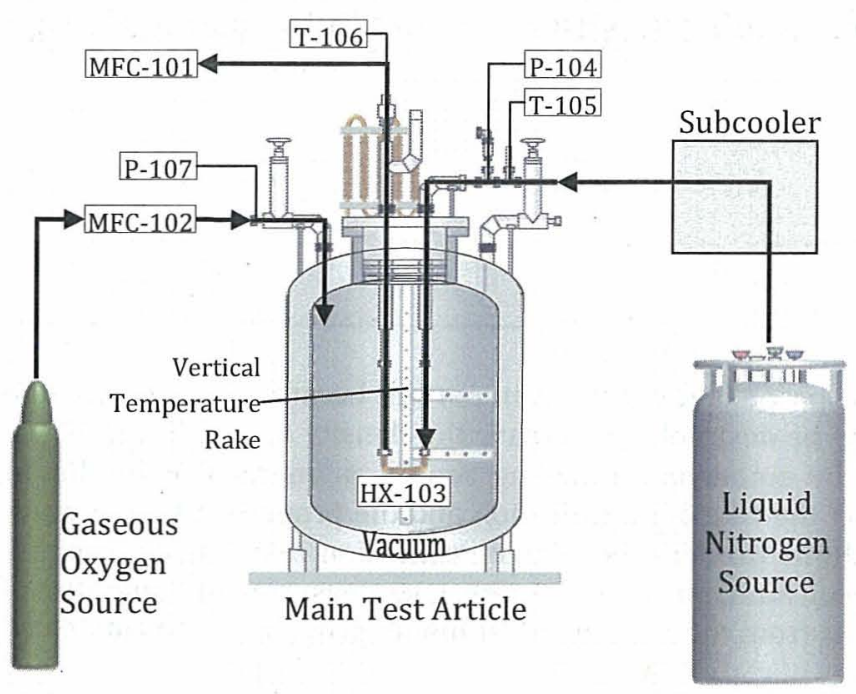

$\begin{array}{ll}\text { MFC-101 } & \text { Coolant Mass Flow Controller } \\ \text { MFC-102 } & \text { Main Test Article Pressure Controller } \\ \text { HX-103 } & \text { Internal Heat Exchanger (Submerged) } \\ \text { P-104 } & \text { Coolant Pressure Transducer } \\ \text { T-105 } & \text { Coolant Inlet Temperature Sensor } \\ \text { T-106 } & \text { Coolant Exit Temperature Sensor } \\ \text { P-107 } & \text { Main Test Article Pressure Transducer } \\ \text { T1 - T20 } & \text { RTD along Vertical Temperature Rake } \\ \text { T21- T28 } & \text { RTD along Horizontal Temperature Rakes }\end{array}$

Figure 1: Mechanical and Instrument Schematic of Test Materials

\subsection{Operation}

The test dewar was filled with 200L of liquid oxygen, so that the liquid height above and below the heat exchanger is $0.152 \mathrm{~m}$ and $0.305 \mathrm{~m}$, respectively. Liquid nitrogen is used as the coolant and flowed from the liquid nitrogen dewar through the heat exchanger inside the test dewar and to the nitrogen mass flow controller. The nitrogen mass flow controller was set at its maximum value of 100 standard liters per minute. The gaseous oxygen source maintained constant pressure within the test dewar, by flowing through the oxygen mass flow controller. The gaseous oxygen mass flow controller was controlled using a PID controller within Labview referencing the main test article pressure, P-107. Three tests were run at a constant pressure of 3 psig, 5 psig, and 7 psig.

\section{Mathematical Model}

Prior to activating the internal heat exchanger, the steady-state condition of the main test dewar begins with a thermally stratified ullage with respect to vertical position and a uniform temperature throughout the liquid. The temperature of the liquid is saturated temperature at the main test dewar storage pressure. Once the internal heat exchanger is activated, the liquid is divided into two zones depending on whether the liquid is above or below the internal heat exchanger. A mathematical model is provided for both zones.

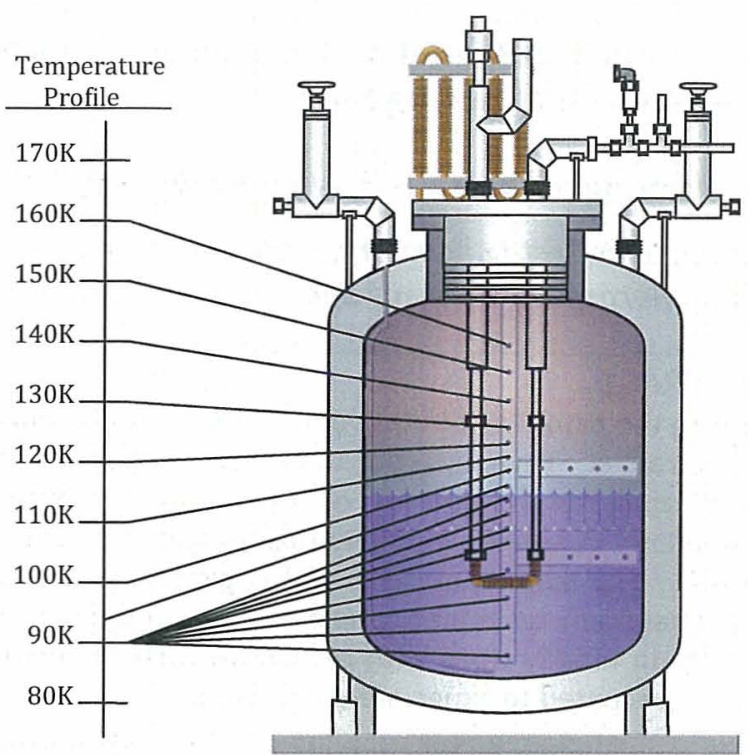

Figure 2: Main Test Article at Steady-State, Initial Condition

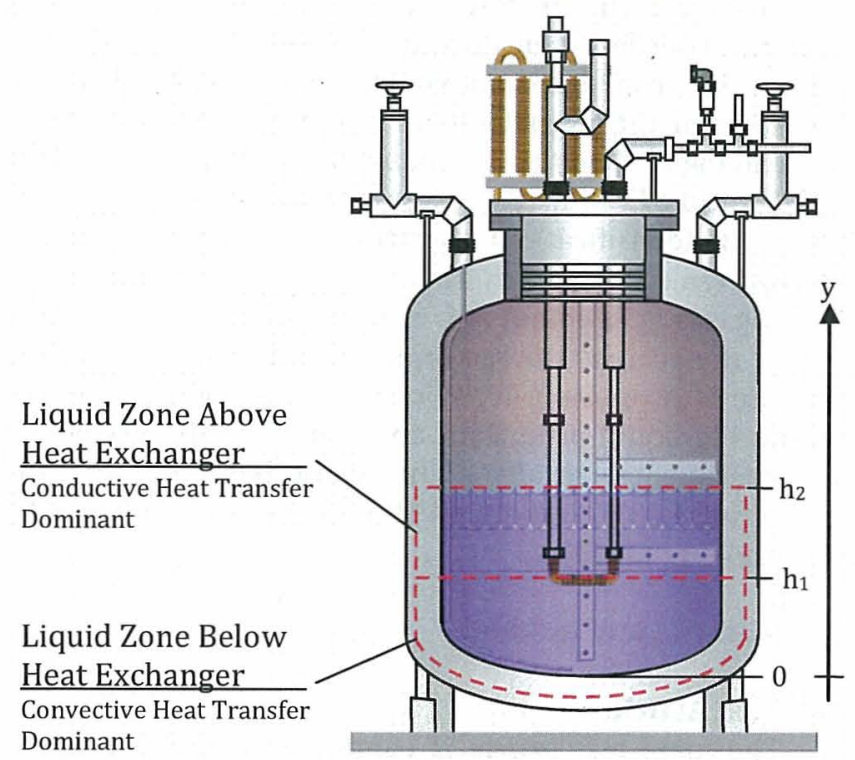

Figure 3: Main Test Article During Heat Exchanger Operation

\subsection{Liquid Zone Above Heat Exchanger}

The liquid zone above the heat exchanger is modeled using the heat equation with constant temperature boundary conditions at both, the top condition and bottom condition. The top boundary is the vapor-liquid interface, which is always at the saturated temperature at the system pressure. Because the main test dewar is operated at constant pressure, the temperature at the top boundary remains constant. The temperature at the bottom boundary is given by the temperature of the internal heat exchanger. The heat equation (1) is solved using the boundary and initial conditions (2), (3), and (4) to arrive at the modeled temperature change rate for the liquid zone above the heat exchanger (5).

Governing Equation: 


$$
\alpha \frac{\partial^{2} \mathrm{~T}(\mathrm{y}, \mathrm{t})}{\partial \dot{y}^{2}}+r=\frac{\partial \mathrm{T}(\mathrm{y}, \mathrm{t})}{\partial \mathrm{t}}
$$

Boundary Conditions:

$$
\begin{gathered}
T\left(\mathrm{~h}_{2}, \mathrm{t}\right)=\mathrm{T}_{\mathrm{sat}} \\
\mathrm{T}\left(\mathrm{h}_{1}, \mathrm{t}\right)=\mathrm{T}_{\mathrm{s}}
\end{gathered}
$$

Initial Condition:

$$
T(\mathrm{y}, 0)=\mathrm{T}_{\mathrm{i}}=\mathrm{T}_{\text {sat }}
$$

$$
\begin{aligned}
& T(y, t) \\
& =\frac{\left(T_{s a t}-T_{s}\right)}{\left(h_{2}-h_{1}\right)}\left(y-h_{1}\right) \\
& +\sum_{n=1}^{\infty} \frac{2\left(T_{s a t}-T_{s}\right)}{n \pi} \sin \left(\frac{n \pi\left(y-h_{1}\right)}{h_{2}-h_{1}}\right) e^{-\alpha\left(\frac{n \pi}{h_{2}-h_{1}}\right)^{2} t}+T_{s}
\end{aligned}
$$

\subsection{Liquid Zone Below Heat Exchanger}

The liquid zone below the heat exchanger is modeled using the heat equation averaged across the entire zone height to estimate the convective heat transfer. The upper boundary condition, modeled as a constant temperature boundary, is given by the temperature of the internal heat exchanger. The lower boundary condition is taken to be insulated. The liquid is initially uniform in temperature with respect to vertical height. The heat equation (6) is solved using the boundary and initial conditions (7), (8), and (9). The solution is provided by (10).

Governing Equation:

$$
\alpha \frac{\partial^{2} \mathrm{~T}(\mathrm{y}, \mathrm{t})}{\partial \mathrm{y}^{2}}=\frac{\partial \mathrm{T}(\mathrm{y}, \mathrm{t})}{\partial \mathrm{t}}
$$

Boundary Conditions:

$$
\begin{aligned}
& \mathrm{T}\left(\mathrm{h}_{1}, \mathrm{t}\right)=\mathrm{T}_{\mathrm{s}} \\
& \left.\frac{\partial \mathrm{T}}{\partial \mathrm{y}}\right|_{\mathrm{y}=0}=0
\end{aligned}
$$

Initial Condition:

$$
\mathrm{T}(\mathrm{y}, 0)=\mathrm{T}_{\text {sat }}
$$

$$
\begin{aligned}
& T(y, t) \\
& =\sum_{n=1}^{\infty} \frac{4\left(T_{s a t}-T_{s}\right)}{(2 n-1) \pi} \sin \left(\frac{(2 n-1) \pi y}{2 h_{1}}\right) e^{-\alpha\left[\left(\frac{2 n-1}{2}\right) \frac{\pi}{h_{1}}\right]^{2} t} \\
& +T_{s}
\end{aligned}
$$

Because the temperature of the heat exchanger is always cooler than or equal to the temperature of the liquid oxygen below the heat exchanger, natural convection occurs in the liquid zone beneath the heat exchanger. The natural convection provides a uniform temperature with respect to height at all times. Thus, the temperature profile, (10), is averaged over the entire height of the liquid zone beneath the heat exchanger to arrive at the modeled temperature change (11).

$$
T(t)=\sum_{n=1}^{\infty} \frac{8\left(T_{s a t}-T_{s}\right)}{[(2 n-1) \pi]^{2}} e^{-\alpha\left[\left(\frac{2 n-1}{2}\right) \frac{\pi}{h_{1}}\right]^{2} t}+T_{s}
$$

\section{Results}

\subsection{Test Results for Liquid Zone Above Heat Exchanger}

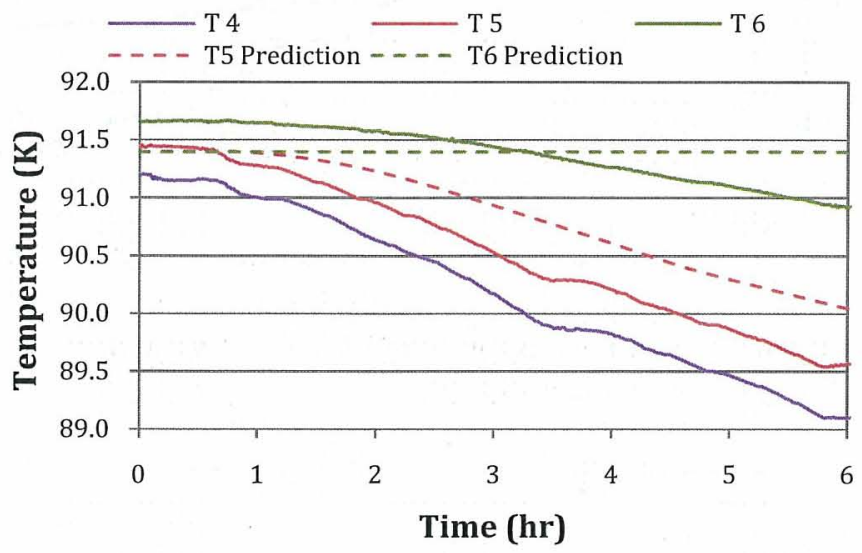

Figure 4: Test Results for Liquid Zone Above the Heat Exchanger (3 psig)

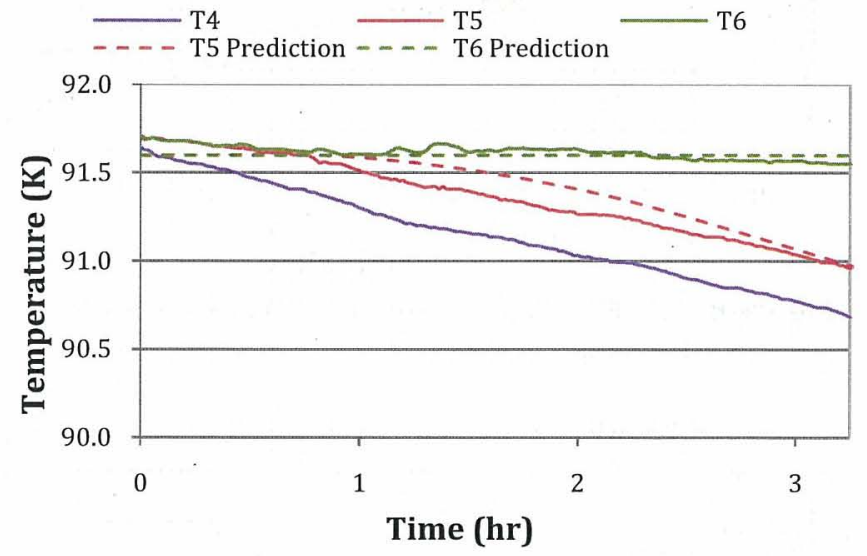

Figure 5: Test Results for Liquid Zone Above the Heat Exchanger (5psig)

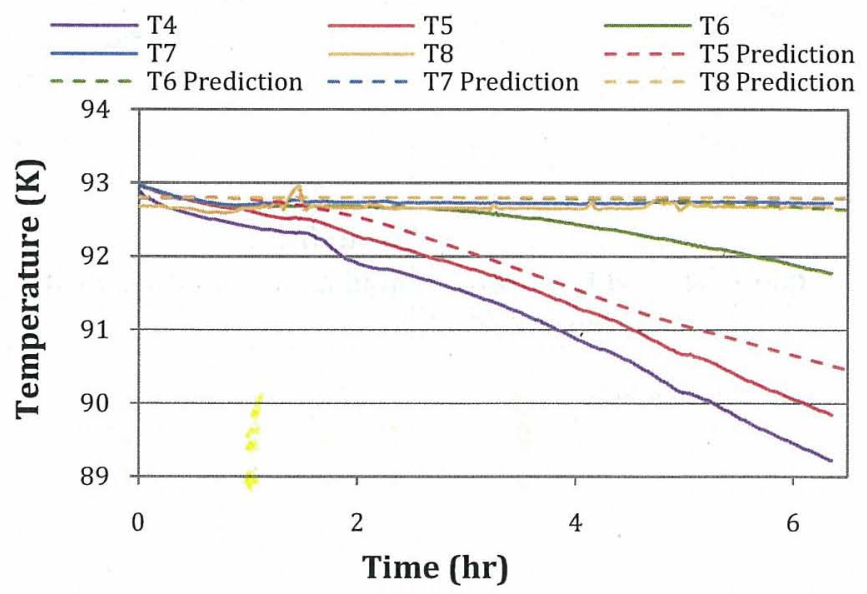


Figure 6: Test Results for Liquid Zone Above the Heat Exchanger (7psig)

\subsection{Test Results for Liquid Zone Below Heat Exchanger}

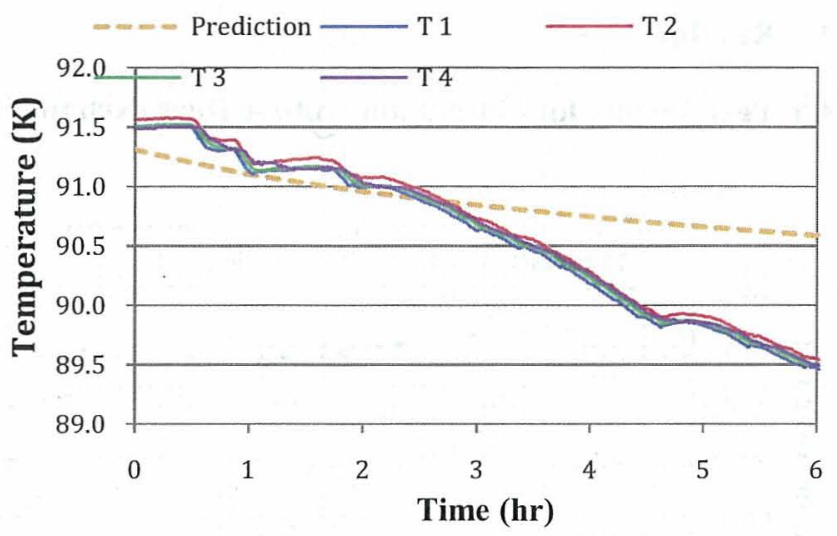

Figure 7: Test Results for Liquid Zone Below the Heat Exchanger (3psig)

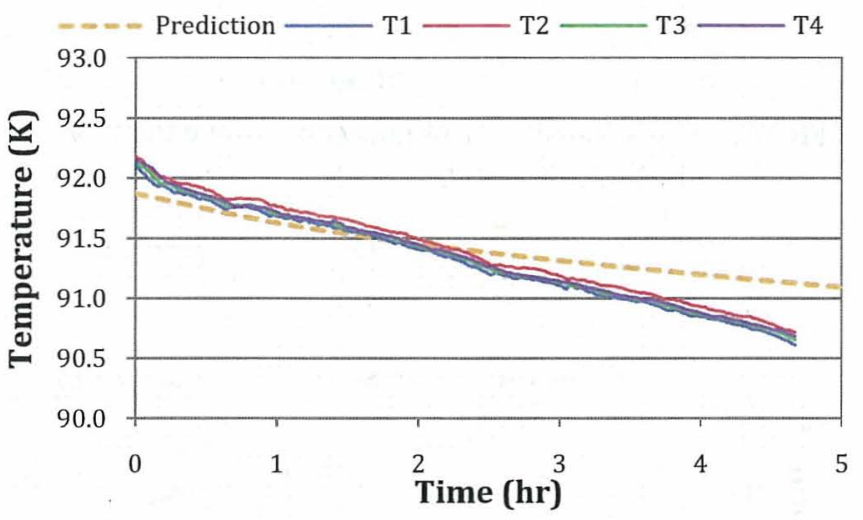

Figure 8: Test Results for Liquid Zone Below the Heat Exchanger (5psig)

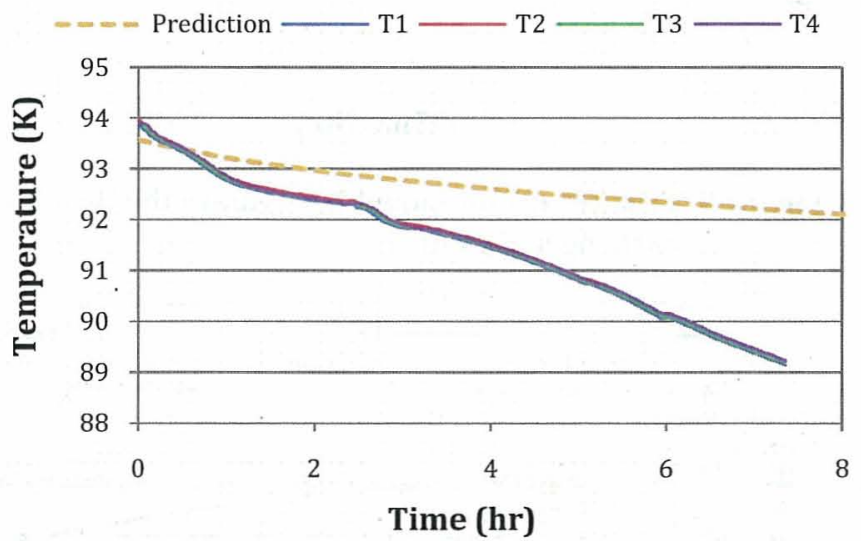

Figure 9: Test Results for Liquid Zone Below the Heat Exchanger (7psig)

\section{Discussion}

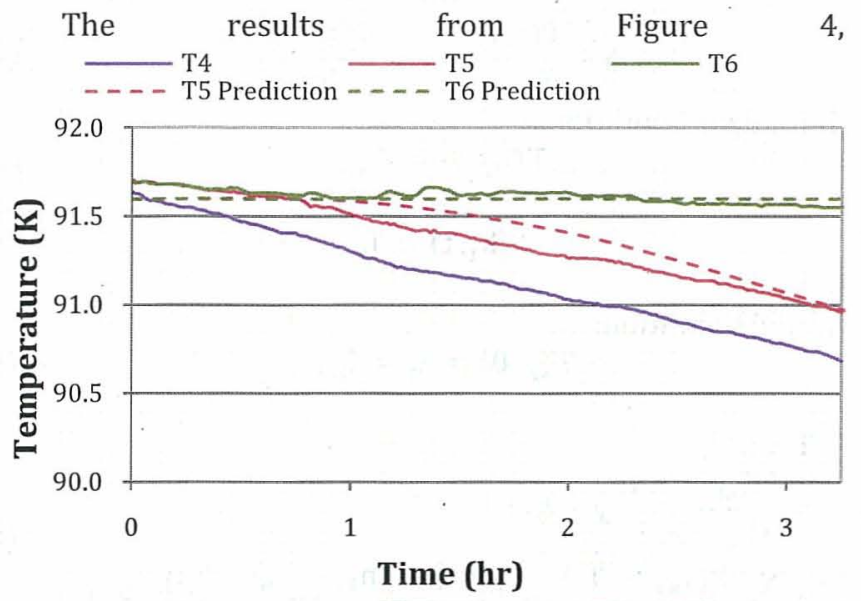

Figure 5, and Figure 6 show that the liquid zone above the heat exchanger experiences conductive heat transfer. Minimal convection occurs within the liquid zone above the heat exchanger as shown by the stratification that grows throughout the heat exchanger operation. The mathematical model, Equation (5), predicts the temperature change rate at the $\mathrm{T} 5$ position with a slight lag. However, with exception of the results in Figure 4, the lag increases for the $\mathrm{T} 6$ position prediction in temperature change rate.

The results from Figure 7, Figure 8, and Figure 9 show the liquid zone below the heat exchanger experiences convective heat transfer. All four position temperature sensors, T1 through T4, maintain the same temperature throughout the heat exchanger operation, which implies a fluid well mixed by convection currents. The mathematical model, Equation (11), predicts a temperature change that is less than the experimental results. The reason for the temperature change rate lag could be that Equation (11), is an average for a conduction model and does not model the convection currents, which increases the heat transfer from the upper boundary at the internal heat exchanger.

The mathematical models presented neglect the heat flux that enters the dewar from the sides in Equation (5), and the heat flux that enters the dewar from the sides and bottom in Equation (11). Thus, Equation (5) and Equation (11) produce models that are one-dimensional. However, from the horizontal temperature sensors, T21 through T24, showed no gradient in the radial direction and was the same temperature as the centerline temperature at the same vertical height. Therefore, the one-dimensional mathematical models are reasonable.

Because the mathematical model for the liquid zone beneath the heat exchanger is an average temperature throughout the liquid zone, the temperature at the upper boundary does not equal temperature of the heat exchanger. Thus, a temperature discontinuity exists between the two models, Equation (5) and Equation (11), at the heat exchanger, and the possibility exists for colder fluid positioned above warmer fluid. In reality, natural convection occurs when a colder, more dense fluid is above a warmer, less dense fluid. Therefore, the 
temperature of the liquid above the heat exchanger can never be less than the temperature below the heat exchanger. Thus, the discontinuity between (5) and (11) can be corrected by mandating that temperature of the liquid above the heat exchanger be the maximum of either Equation (5) or Equation (11). Equation (12) and Equation (13) provide the unified temperature model.

$\mathrm{T}(\mathrm{y}, \mathrm{t})=\max \left\{\begin{array}{c}\text { Equation (5) } \\ \text { Equation (11) }\end{array}\right.$ for $\mathrm{h}_{1} \leq \mathrm{y} \leq \mathrm{h}_{2}$

$T(y, t)=$ Equation (11) for $0 \leq y<h_{1}$

Figure 10 shows the predicted vertical temperature profile, during heat exchanger operation. The vertical temperatures are represented by $\mathrm{T} 1-\mathrm{T} 12$, which are located vertically in the main test dewar. The vapor-liquid interface is at the T8 and the heat exchanger is located at the T4. The left portion of Figure 10 shows the temperature discontinuity between the mathematical models, (5) and (11). The right portion of Figure 10 shows the unified temperature models from Equation (12) and Equation (13). Figure 11 shows the combined experimental data of Figure 6 and Figure 9 for comparison with Figure 10.

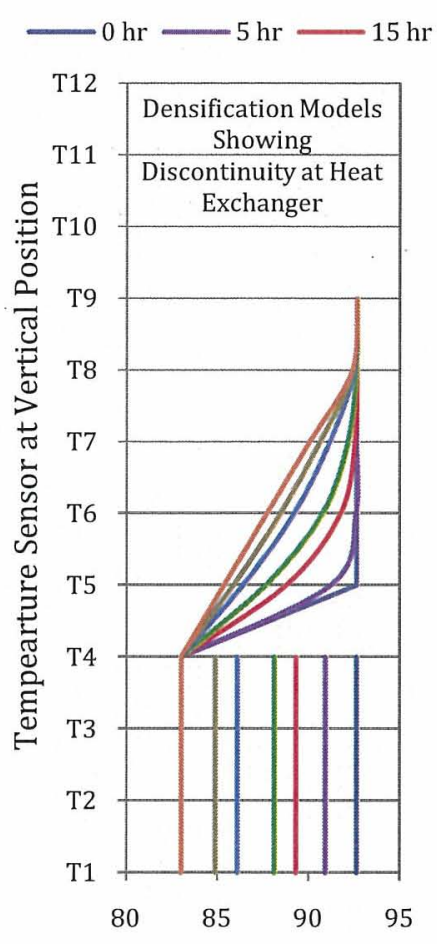

Temperature (K)

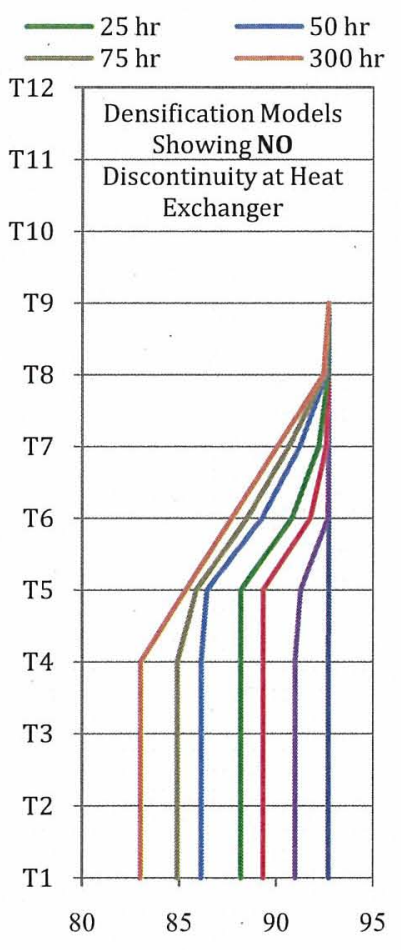

Temperature (K)
Figure 10: Exposure and Correction of the Discontinuity Between Both Mathematical Models

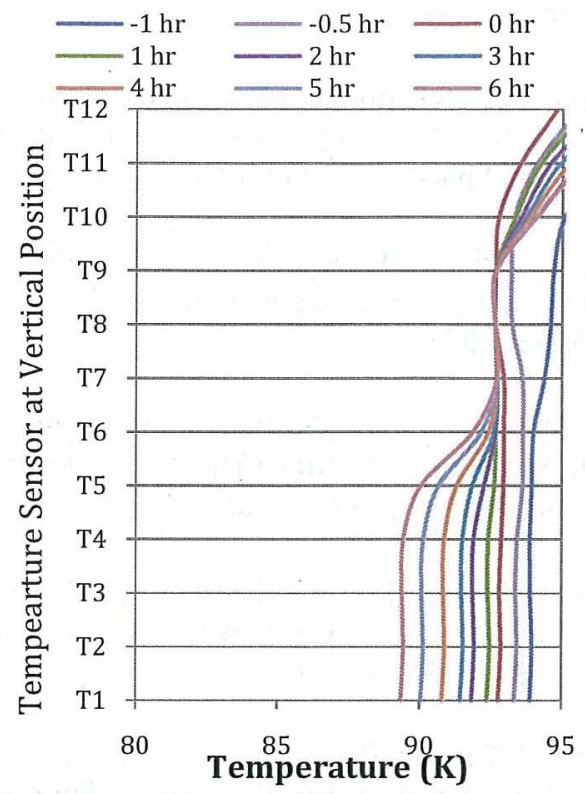

Figure 11: Test Results for the Liquid (7psig) Shown as the Temperature Profile for the Vertical Position.

The coolant removed about $330 \mathrm{~W}$ from the main test article. However, not all of the heat removed was used to cool the liquid oxygen. The heat transfer from the ambient was approximately $20 \mathrm{~W}$, according to the experimental normal evaporation rate. Also, a portion of the gaseous oxygen that flows into the ullage is cooled and liquefied, accounting for $180 \mathrm{~W}$. Therefore, $130 \mathrm{~W}$ of heat was removed from the liquid oxygen.

The major benefit for densification within the storage tank under positive pressure allows the use of a low power cooling source that densifies the propellant over time while inhibiting atmospheric intrusion. Same species pressurization also assures that propellant purity will be maintained throughout the densification process. However, as shown above, the liquid below the heat exchanger can be fully densified, while the liquid above the heat exchanger is partially densified. Also, cooling the pressurant gas required about $55 \%$ of the cooling available from the heat exchanger, decreasing the densification rate of the liquid.

\section{Conclusions}

The use of a submerged cooling source is a viable method to obtain densified and sub-cooled propellants. Also, same species pressurant can be used to maintain positive pressure of a storage tank during the densification operation. This study confirmed that conduction heat transfer dominates the fluid above the heat exchanger, while convection heat transfer dominates the fluid below the heat exchanger. 


\section{References}

[1] M. M. Fazah, STS Propellant Densification Feasibility Study Data Book, NASA Technical Memorandum 108467, NASA, Marshall Space Flight Center, AL, 1994.

[2] M.S. Haberbusch, A.F. Skaff, et al., Modeling the RL10 with Densified Liquid Hydrogen and Oxygen Propellants, AIAA () (2002) 3597.

[3] T. Lak, M. Lozano, et al., Advancement in Cryogenic Propulsion System Performance Through Propellant Densification, AIAA O (1996) 3123.

[4] William D. Greene, David A. Vaughn, Simulation and Testing of In-Tank Propellant Densification For Launch Vehicles, AIAA () (1998) 3688.

[5] Thomas M. Tomsik, Performance Tests of a Liquid Hydrogen Propellant Densification Ground Support System for the X33/RLV, AIAA O (1997) 2976-2992.

[6] T.I. Lak, M.E. Lozano, et al., Propellant Densification Without Use of Rotating Machinery, AIAA () (2002) 35993608 .

[7] William U. Notardonato, Wesley L. Johnson, et al., Experimental Results of Integrated Refrigeration and Storage System Testing, in: Advances in Cryogenic Engineering, American Institute of Physics, Melville, NY, 2009, pp. 1369-1376.

[8] William U. Notardonato, Wesley L. Johnson, et al.,Integrated Refrigeration and Storage System - Heat Exchanger Characterization, Final Report, NASA, Kennedy Space Center, 2009.

\section{Variables}

$\begin{array}{ll}\mathrm{n} & \text { integer used for summation }(\mathrm{J} \\ \mathrm{h} & \text { height }(\mathrm{m}) \\ \mathrm{t} & \text { time }(\mathrm{s}) \\ \mathrm{T} & \text { temperature }(\mathrm{K}) \\ \mathrm{r} & \text { non-homogeneous component of heat equation } \\ \mathrm{y} & \text { vertical component of coordinate system }(\mathrm{m}) \\ \alpha & \text { thermal diffusivity }\left(\mathrm{m}^{2} / \mathrm{s}\right) \\ & \\ \text { Subscripts } \\ 1 & \text { vertical height at heat exchanger } \\ 2 & \text { vertical height at vapor liquid interface } \\ \text { sat } & \text { saturated temperature } \\ \mathrm{s} & \text { heat exchanger surface temperature }\end{array}$

